\title{
Interdependence of Bitcoin and Other Crypto Money Indicators: CD Vine Copula Approach
}

\author{
Ayşe METIN KARAKAŞ ${ }^{1 *}$, Aslıhan DEMİR ${ }^{2}$, Sinan ÇALIK ${ }^{2}$ \\ ${ }^{I}$ Bitlis Eren University, Department of Mathematics, Bitlis, Turkey \\ ${ }^{2}$ Firat University, Department of Mathematics, Elaziğ, Turkey \\ (ORCID: 0000-0003-3552-0105) (ORCID: 0000-0003-4532-1564) (ORCID: 0000-0002-4258-1662)
}

\begin{abstract}
In recent years, there has been a growing interest on the combination of copulas with mixture model. The combination of vine copulas incorporated into a finite mixture model is also helpful to capture secret structures in a data. This paper aims to examine the relationship between bitcoin and other crypto money indicators with the CD Vine Copula Approach method. In the study, we use closing prices of Bitcoin, Bitcoin Cash, Ethereum, Litecoin, and IOTA. The results show that there is a strong dependence between bitcoin and prominent financial indicators.
\end{abstract}

Keywords: Vine Copula, C Vine copula, D vine copula.

\section{Bitcoin ve Diğer Kripto Para Göstergelerinin Bağımsızlı̆ğ: CD Vine Copula Yaklaşımı}

\begin{abstract}
Öz
Son yıllarda, kopulaların karışım modeli ile birleşimine olan ilgi giderek artmaktadır. Sonlu bir karışım modeline dahil edilen asma kopulaların kombinasyonu, bir verideki gizli yapıların yakalanmasına da yardımcı olur. Bu makale, Bitcoin ve diğer kripto para göstergeleri arasındaki ilişkiyi CD Vine Copula Approach yöntemiyle incelemeyi amaçlamaktadır. Çalışma da Bitcoin, Bitcoin Cash, Ethereum, Litecoin ve IOTA finansal göstergelerinin kapanış fiyatlarını kullanıyoruz. Sonuçlar, bitcoin ve önemli finansal göstergeler arasında güçlü bir bağımlılık olduğunu göstermektedir.
\end{abstract}

Anahtar Kelimeler: Vine Copula, C Vine copula, D vine copula.

\section{Introduction}

Bitcoin is a peer-to-peer version of electronic cash [1]. Classified as cryptocurrency, Bitcoin has become popular in recent years. The currency can be said to have an intriguing logic [2]. Although the Bitcoin world is prospering, there are several threats for users with regard to legal status and possible government sanctions [3]. Despite having detractors, Bitcoin achieved an important role and became an emerging force in the financial world after mid-2013 [4].

Rather than being issued by central organization such as a government or bank, it is completely reliant on cryptography, and the whole process of minting, storing and transfer is carried out by network of users [5]. Bitcoin was not created or controlled by a central organization, but by process called "mining", one of the key concepts in Bitcoin world. Valid transactions are compiled in blocks, then these and previously accepted blocks are added to the ledger. All transactions must take place in the network, called block chain, thus preventing users from double spending [6]. A major problem with Bitcoin is the possibility of double-spending [7], and therefore delayed payment verification is required [8]. To avoid the double spending problem, the system depends on digital signatures to confirm ownership, and a public history of transactions [9]. There are some important general assumptions with regard to Bitcoin, such as stakeholders must accept the rules and validity of transactions, and most

"Corresponding author: akarakas@beu.edu.tr Received: 17.07.2020, Accepted: 19.11.2020 
importantly, it must be confirmed that Bitcoin has a value [10]. Bitcoin is represented by a series of signals called transaction, which have several inputs and outputs [11]. Bitcoin is established on a transaction registry dispersed across all participants [12]. Hence, this is a Proof-of-Work-based currency, in that users themselves can create crypto coin, requiring a heavy computational burden. In this paper, we used the copula approach to describe the dependence structure of variables of interest. [13] first introduced the copula theory to allow flexible description of the dependence between variables. [14] provided a thorough description of copulas from a mathematic perspective. [15] first employed the copula in the area of finance, and since has been widely applied in the field of financial risk management and portfolio decision problems. [16] made a seminal contribution to the advent of pricing multivariate option by using copula. [17] proposed Copula-GARCH models, which introduced the dynamic copula period. [18] reviewed the application of copula in financial time series. [19] supplied references, leading to the extensive list of ARCH acronyms used in the literature. [17] established model selection criteria with the ability to correctly identify the data generating process in simulated data. [21] reproduced a group of appropriately adjusted information criteria for selection of models from the ARGARCH family. [22] examine the dependence between electricity spot markets in core European countries including France, Germany, Austria and Switzerland based on copula models. Of the ten different copulas with both time invariant and varying parameters currently in use, the empirical results show that time-varying Student-t copula is the best model for the sample data[23] explores the bivariate dependence structure between the US Dollar and four major currencies (EUR, GBP, CAD, JPY) using daily data for the time-span 1999-2014, and utilize different time-invariant and time-varying copula functions with different forms of tail dependence, and find a positive dependence between all exchange rates. In this study, we investigate the dependence among the crypto money indicators, for this, we use $\mathrm{R}$ vine, $\mathrm{C}$ vine and $\mathrm{D}$ vine copula modelling.

\section{Material and Method}

\subsection{Copula Functions}

The copula function is proposed to measure dependence of multivariate variables. Based on Sklar's wellknown theorem [13], copulas allow the implementation of the division of the specification of a multivariate model into two parts: the marginal distributions on one side, the dependence structure (copula) on the other. Let $X$ and $Y$ be random variables with continuous distribution functions $F_{X}$ and $F_{Y}$, which are uniformly distributed on the interval $[0,1]$. Then, there is a copula such that for all $x, y \in R$,

$$
F_{X Y}(X, Y)=C\left(F_{X}(X), F_{Y}(Y) .\right.
$$

The copula $C$ for $(X, Y)$ is the joint distribution function for the pair $F_{X}(X), F_{Y}(Y)$ provided $F_{X}$ and $F_{Y}$ continuous. The copula $C$ for $(X, Y)$ is the joint distribution function for the pair $F_{X}(X), F_{Y}(Y)$ provided $F_{X}$ and $F_{Y}$ continuous. The joint probability density of the variables $X$ and $Y$ is obtained from the copula density $(u, v)=\frac{\partial^{2} C(u, v)}{\partial u \partial v}$, as follows:

$$
f_{x y}(x, y)=c(u, v) f_{x}(\mathrm{x}) f_{y}(y),
$$

where $f_{x}(\mathrm{x})$ and $f_{y}(y)$ are the marginal densities of the random variables $X$ and $Y$. According to [13], an n-dimensional joint distribution can be decomposed into its n-univariate marginal distributions and an n-dimensional copula. In the extension of Sklar's theorem to continuous conditional distributions, [18] shows that the lower (left) and upper (right) tail dependence of two random variables is given for the copula as:

$$
\begin{gathered}
\lambda_{l}=\lim _{u \rightarrow 0} P\left(\mathrm{~F}_{x}(x) \leq u \mid F_{y}(x) \leq u\right)=\lim _{u \rightarrow 0} C(u, u) / u \\
\lambda_{u}=\lim _{u \rightarrow 1} P\left(\mathrm{~F}_{x}(x)>\mathrm{u} \mid F_{y}(x)>u\right)=\lim _{u \rightarrow 1} 1-2 u-C(u, u) / 1-u
\end{gathered}
$$


where $\lambda_{l}$ and $\lambda_{u} \in[0,1]$.

\subsection{Vine Copula}

A vine copula structure is simply defined as a nested set of trees describing the pairwise copula functions unconditionally at the first tree and conditionally for the rest of connected trees. This construction is presented by Bedford and Cooke as follows;

\subsubsection{Vine Copula}

It is a type of regular vine distribution for which each tree has a unique node that is connected to all other nodes of the tree. It uses only star like trees and it is useful for ordering by importance. the corresponding probability density function can be written as,

$$
\begin{aligned}
& \prod_{k=1}^{n} f\left(x_{k}\right) \prod_{j=1}^{n-1} \prod_{i=1}^{n-j} c_{j, j+i \mid 1, \ldots, j-1} F\left(x_{j} \mid x_{1}, \ldots, x_{j-1}\right), F\left(x_{j+i} \mid x_{1}, \ldots, x_{j-1}\right) \\
& f\left(x_{1}, x_{2}, x_{3}, x_{4}, x_{5}\right)=f_{1}\left(x_{1}\right), f_{2}\left(x_{2}\right) \cdot f_{3}\left(x_{3}\right), f_{4}\left(x_{4}\right), f_{5}\left(x_{5}\right) \\
& \text {. } c_{12}\left\{F_{1}\left(x_{1}\right), F_{2}\left(x_{2}\right)\right\} . c_{13}\left\{F_{1}\left(x_{1}\right), F_{3}\left(x_{3}\right)\right\} . c_{14}\left\{F_{1}\left(x_{1}\right), F_{4}\left(x_{4}\right)\right\} \\
& \text {. } c_{15}\left\{F_{1}\left(x_{1}\right), F_{5}\left(x_{5}\right)\right\} . c_{23 \mid 1}\left\{F\left(x_{2} \mid x_{1}\right), F\left(x_{3} \mid x_{1}\right)\right\} \\
& \text {. } c_{24 \mid 1}\left\{F\left(x_{2} \mid x_{1}\right), F\left(x_{4} \mid x_{1}\right)\right\} . c_{25 \mid 1}\left\{F\left(x_{2} \mid x_{1}\right), F\left(x_{5} \mid x_{1}\right)\right\} \text {. } \\
& \text {. } c_{43 \mid 12}\left\{F\left(x_{4} \mid x_{1}, x_{2}\right), F\left(x_{3} \mid x_{1}, x_{2}\right)\right\} . c_{45 \mid 12}\left\{F\left(x_{4} \mid x_{1}, x_{2}\right), F\left(x_{5} \mid x_{1}, x_{2}\right)\right\} \\
& \text {. } c_{35 \mid 124}\left\{F\left(x_{3} \mid x_{1}, x_{2}, x_{4}\right), F\left(x_{5} \mid x_{1}, x_{2}, x_{4}\right)\right\}
\end{aligned}
$$

For example, for 5 dimensional multivariate density, assuming that the first variable is selected as the root node of the first tree (T1) and the corresponding C-vine tree structure is represented in Figure 1 ;

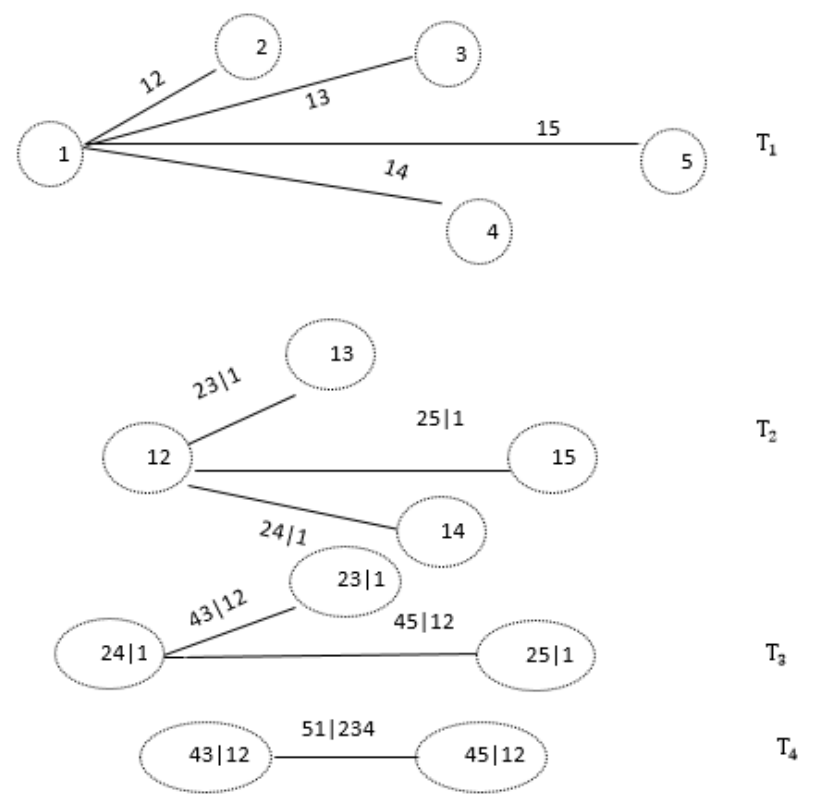

Figure 1. Tree Structure of C-Vine for 5 variables

\subsubsection{Vine Copula}

D-vine is another special case for regular vine tree structure having no node in any tree is connected to more than two edges. It uses only path like trees and beneficial for temporal ordering of variables. its density function can be written as; 


$$
\begin{aligned}
& \prod_{k=1}^{n} f\left(x_{k}\right) \prod_{j=1}^{n-1} \prod_{i=1}^{n-j} c_{i, i+j \mid i+1, \ldots, i+j-1} F\left(x_{i} \mid x_{i+1}, \ldots, x_{i+j-1}\right), F\left(x_{i+j} \mid x_{i+1}, \ldots, x_{i+j-1}\right) \\
& f\left(x_{1}, x_{2}, x_{3}, x_{4}, x_{5}\right)=f_{1}\left(x_{1}\right), f_{2}\left(x_{2}\right), f_{3}\left(x_{3}\right), f_{4}\left(x_{4}\right), f_{5}\left(x_{5}\right) \\
& . c_{52}\left\{F_{5}\left(x_{5}\right), F_{2}\left(x_{2}\right)\right\}, c_{23}\left\{F_{2}\left(x_{2}\right), F_{3}\left(x_{3}\right)\right\}, c_{34}\left\{F_{3}\left(x_{3}\right), F_{4}\left(x_{4}\right)\right\} \\
& . c_{41}\left\{F_{4}\left(x_{4}\right), F_{1}\left(x_{1}\right)\right\}, c_{53 \mid 2}\left\{F\left(x_{5} \mid x_{2}\right), F\left(x_{3} \mid x_{2}\right)\right\} \\
& . c_{24 \mid 3}\left\{F\left(x_{2} \mid x_{3}\right), F\left(x_{4} \mid x_{3}\right)\right\} . c_{31 \mid 4}\left\{F\left(x_{3} \mid x_{4}\right), F\left(x_{1} \mid x_{4}\right)\right\} \\
& . c_{54 \mid 23}\left\{F\left(x_{5} \mid x_{2}, x_{3}\right), F\left(x_{4} \mid x_{2}, x_{3}\right)\right\}, c_{21 \mid 34}\left\{F\left(x_{2} \mid x_{3}, x_{4}\right), F\left(x_{1} \mid x_{3}, x_{4}\right)\right\} \\
& . c_{51 \mid 234}\left\{F\left(x_{5} \mid x_{2}, x_{3}, x_{4}\right), F\left(x_{1} \mid x_{2}, x_{3}, x_{4}\right)\right\}
\end{aligned}
$$

For example, for 5 dimensional multivariate densities, D-vine model is represented by Figure 2;

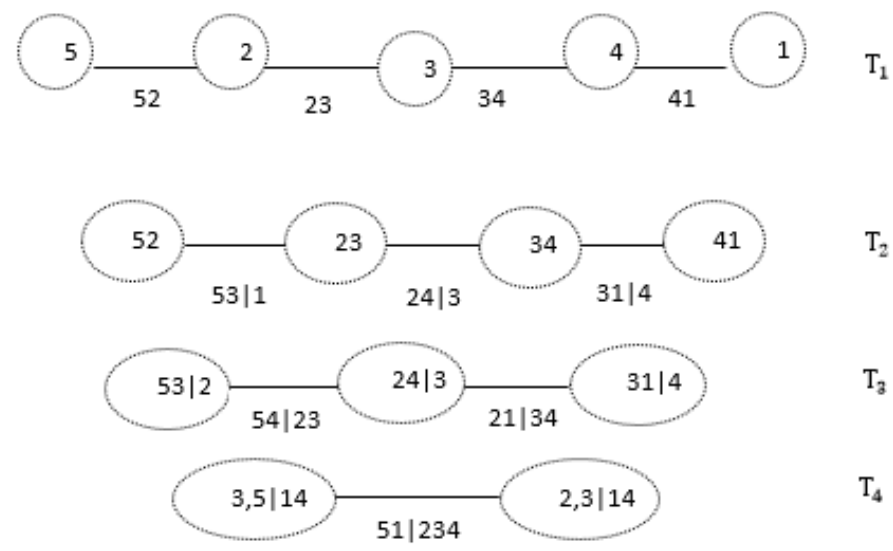

Figure 2. Tree Structure of D-Vine for 5 variables

\section{Results}

\subsection{Data Set}

We use the daily closing prices of crypto money indicators in 2018-2019. Graphical representations of the data employed are shown in figures 3 , figure 4.
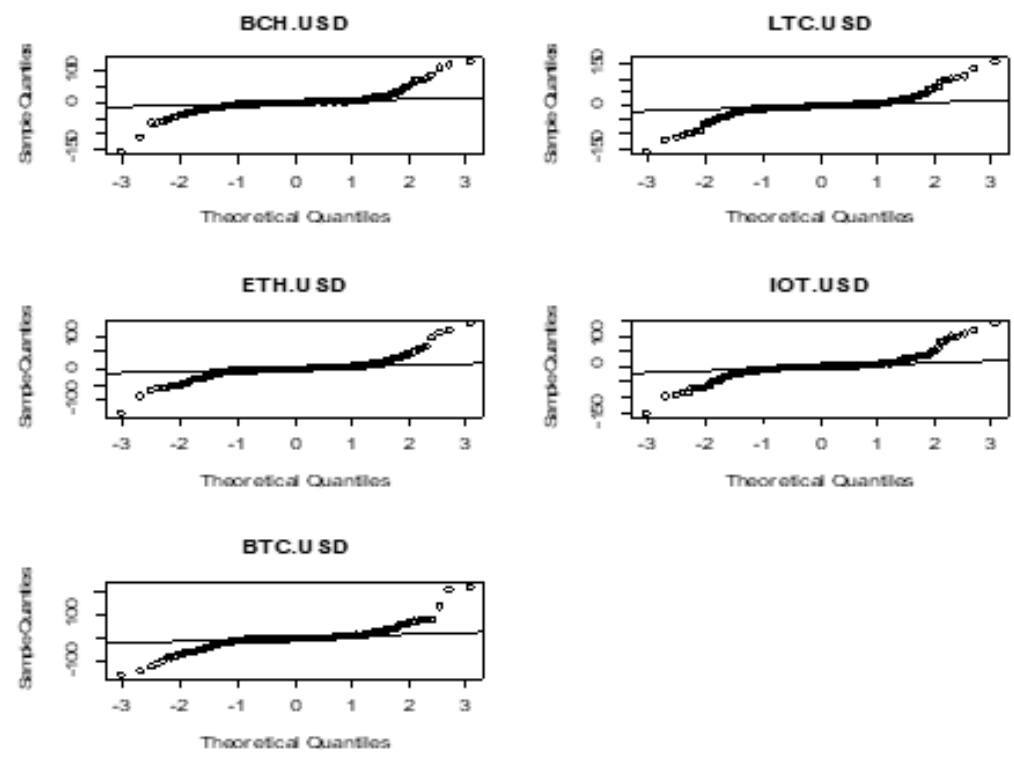

Figure 3. Quantile Graphs data of daily crypto money indicators 

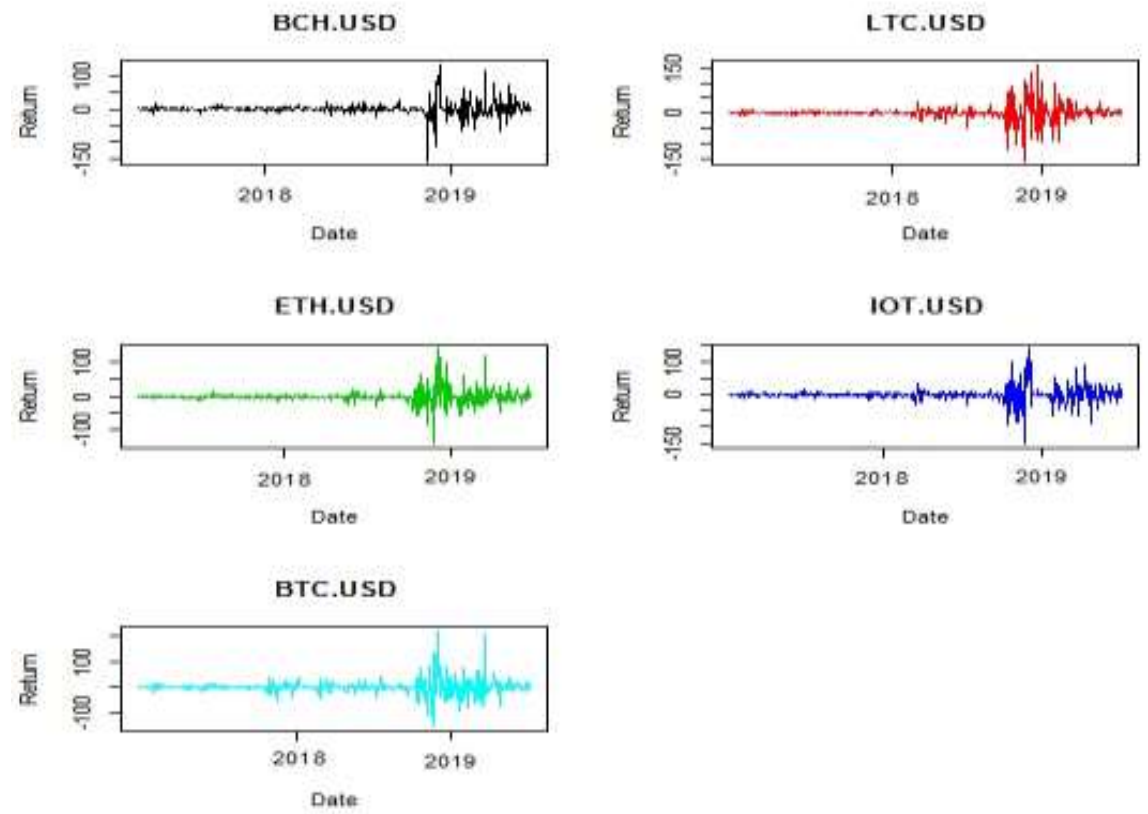

Figure 4. Returns Graphs of Daily crypto money indicators
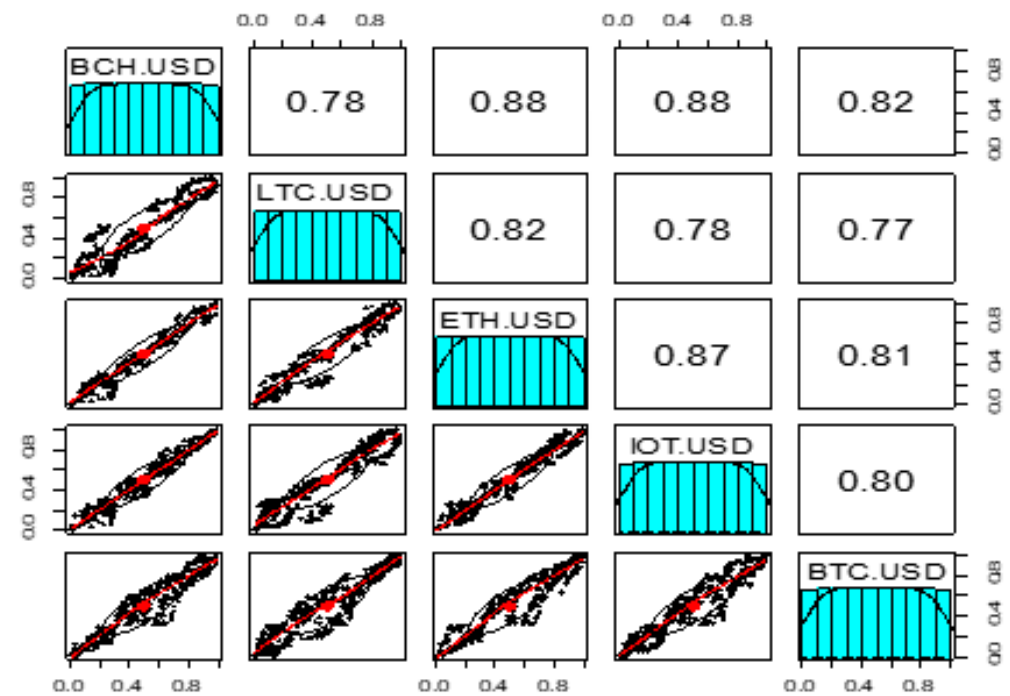

0.77
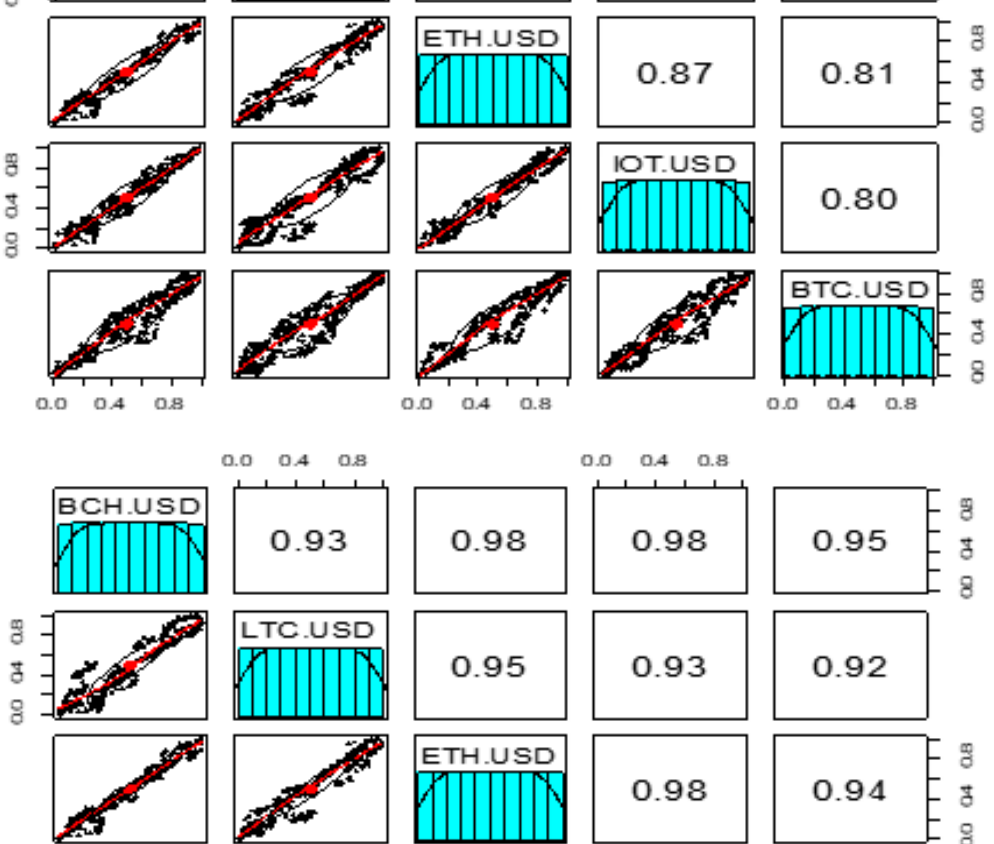

0.92
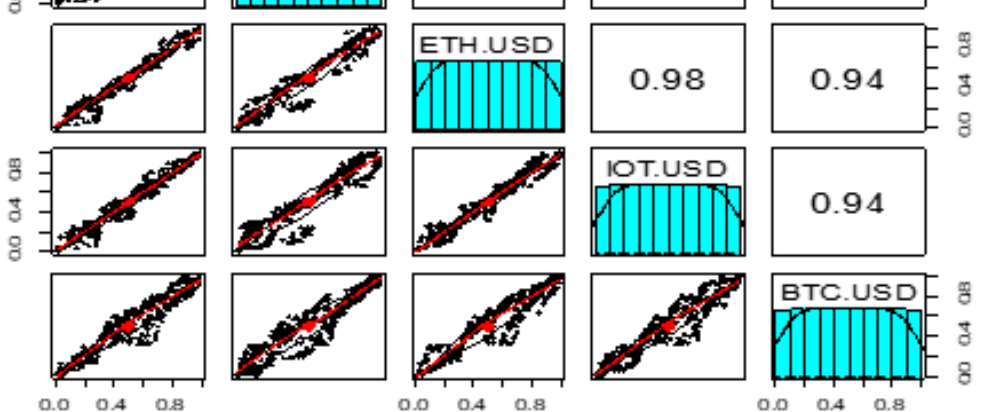

Figure 5. Kendall Tau and Spearman Rho for crypto money indicators, respectively 


\subsection{Vine Copula Approach}

The empirical distribution functions used in modelling the dependence of crypto money indicators data pairs are as shown in_Figure 5, 6, 7, 8 and Table 3, 4, 5, 6. For this, we used C Vine and D Vine copula. In Table 3, 4 the preferred copula families for branching and the parameter summaries of these families are given. In Figure 6 and Figure 7, for C Vine, D Vine matrix summaries and appropriate branch graphs are shown. From Table 3, 4, 5, 6 and Figure 6, 7, for dependency structure of crypto money indicators, $\mathrm{D}$ vine branching was found to be appropriate according to the information criteria.

\subsubsection{Vine Copula Results}

Table 3. C Vine Copula Matrix Summary for crypto money indicators

\begin{tabular}{|c|c|c|c|c|c|c|c|c|c|c|c|c|c|c|c|c|c|}
\hline 1 & {$[, \mathbf{1}]$} & {$[, 2]$} & {$[, 3]$} & {$[, 4]$} & {$[, 5]$} & 2 & {$[, 1]$} & {$[, 2]$} & {$[, 3]$} & {$[, 4]$} & {$[, 5]$} & 3 & {$[, 1]$} & {$[, 2]$} & {$[, 3]$} & {$[, 4]$} & {$[, 5]$} \\
\hline$[1]$, & 1 & 0 & 0 & 0 & 0 & {$[1]$,} & 1 & 0 & 0 & 0 & 0 & {$[1]$,} & 1 & 0 & 0 & 0 & 0 \\
\hline$[2]$, & 2 & 2 & 0 & 0 & 0 & {$[2]$,} & 2 & 2 & 0 & 0 & 0 & {$[2]$,} & 2 & 2 & 0 & 0 & 0 \\
\hline$[3]$, & 5 & 5 & 5 & 0 & 0 & {$[3]$,} & 4 & 4 & 4 & 0 & 0 & {$[3]$,} & 4 & 4 & 4 & 0 & 0 \\
\hline$[4]$, & 4 & 4 & 4 & 4 & 0 & {$[4]$,} & 5 & 5 & 5 & 5 & 0 & {$[4]$,} & 3 & 3 & 3 & 3 & 0 \\
\hline$[5]$, & 3 & 3 & 3 & 3 & 3 & {$[5]$,} & 3 & 3 & 3 & 3 & 3 & {$[5]$,} & 5 & 5 & 5 & 5 & 5 \\
\hline \multicolumn{6}{|c|}{ AIC : -4874.909} & \multicolumn{6}{|c|}{ AIC : -4857.973} & \multicolumn{6}{|c|}{ AIC: -4850.965} \\
\hline 4 & {$[, 1]$} & {$[, 2]$} & {$[, 3]$} & {$[, 4]$} & {$[, 5]$} & 5 & {$[, 1]$} & {$[, 2]$} & {$[, 3]$} & {$[, 4]$} & {$[, 5]$} & 6 & {$[, 1]$} & {$[, 2]$} & {$[, 3]$} & {$[, 4]$} & {$[, 5]$} \\
\hline$[1]$, & 1 & 0 & 0 & 0 & 0 & {$[1]$,} & 1 & 0 & 0 & 0 & 0 & {$[1]$,} & 1 & 0 & 0 & 0 & 0 \\
\hline$[2]$, & 2 & 2 & 0 & 0 & 0 & {$[2]$,} & 2 & 2 & 0 & 0 & 0 & {$[2]$,} & 2 & 2 & 0 & 0 & 0 \\
\hline$[3]$, & 3 & 3 & 3 & 0 & 0 & {$[3]$,} & 3 & 3 & 3 & 0 & 0 & {$[3]$,} & 5 & 5 & 5 & 0 & 0 \\
\hline$[4]$, & 4 & 4 & 4 & 4 & 0 & {$[4]$,} & 5 & 5 & 5 & 5 & 0 & {$[4]$,} & 3 & 3 & 3 & 3 & 0 \\
\hline$[5]$, & 5 & 5 & 5 & 5 & 5 & {$[5]$,} & 4 & 4 & 4 & 4 & 4 & {$[5]$,} & 4 & 4 & 4 & 4 & 4 \\
\hline \multicolumn{6}{|c|}{ AIC: -4850.101} & \multicolumn{6}{|c|}{ AIC $:-4733.960$} & \multicolumn{6}{|c|}{ AIC : -4706.239} \\
\hline
\end{tabular}

Table 4. C Vine Copula Family Summary for crypto money indicators

\begin{tabular}{|c|c|c|c|c|c|c|c|c|}
\hline Tree & Edge & $\begin{array}{c}\text { Family } \\
\text { No. }\end{array}$ & Copula & Par1 & Par2 & Tau & $\begin{array}{c}\text { Lower tail } \\
\text { dependency }\end{array}$ & $\begin{array}{l}\text { Upper tail } \\
\text { dependency }\end{array}$ \\
\hline \multirow[t]{4}{*}{1} & 3,1 & 5 & $\mathrm{~F}$ & 29.96 & 0.00 & 0.87 & - & - \\
\hline & 3,2 & 5 & $\mathrm{~F}$ & 18.75 & 0.00 & 0.81 & - & - \\
\hline & 3,5 & 1 & $\mathrm{~N}$ & 0.95 & 0.00 & 0.79 & - & - \\
\hline & 3,4 & 5 & $\mathrm{~F}$ & 27.41 & 0.00 & 0.86 & - & - \\
\hline \multirow[t]{3}{*}{2} & 4,$1 ; 3$ & 7 & BB1 & 0.73 & 1.20 & 0.39 & 0.22 & 0.45 \\
\hline & 4,$2 ; 3$ & 114 & Tawn180 & 1.68 & 0.17 & 0.12 & - & 0.14 \\
\hline & 4,$5 ; 3$ & 1 & $\mathrm{~N}$ & 0.30 & 0.00 & 0.19 & - & - \\
\hline \multirow[t]{2}{*}{3} & 5,$1 ; 4,3$ & 10 & BB8 & 1.99 & 0.88 & 0.24 & - & - \\
\hline & 5,$2 ; 4,3$ & 114 & Tawn180 & 4.91 & 0.12 & 0.12 & - & 0.12 \\
\hline \multirow[t]{2}{*}{4} & 2,$1 ; 5,4,3$ & 224 & Tawn2_90 & -1.41 & 0.18 & $\begin{array}{c}- \\
0.09\end{array}$ & - & - \\
\hline & & type: & ne $\log \mathrm{Li}$ & 2452 & AIC & -4874 & BIC: -4813. & \\
\hline
\end{tabular}



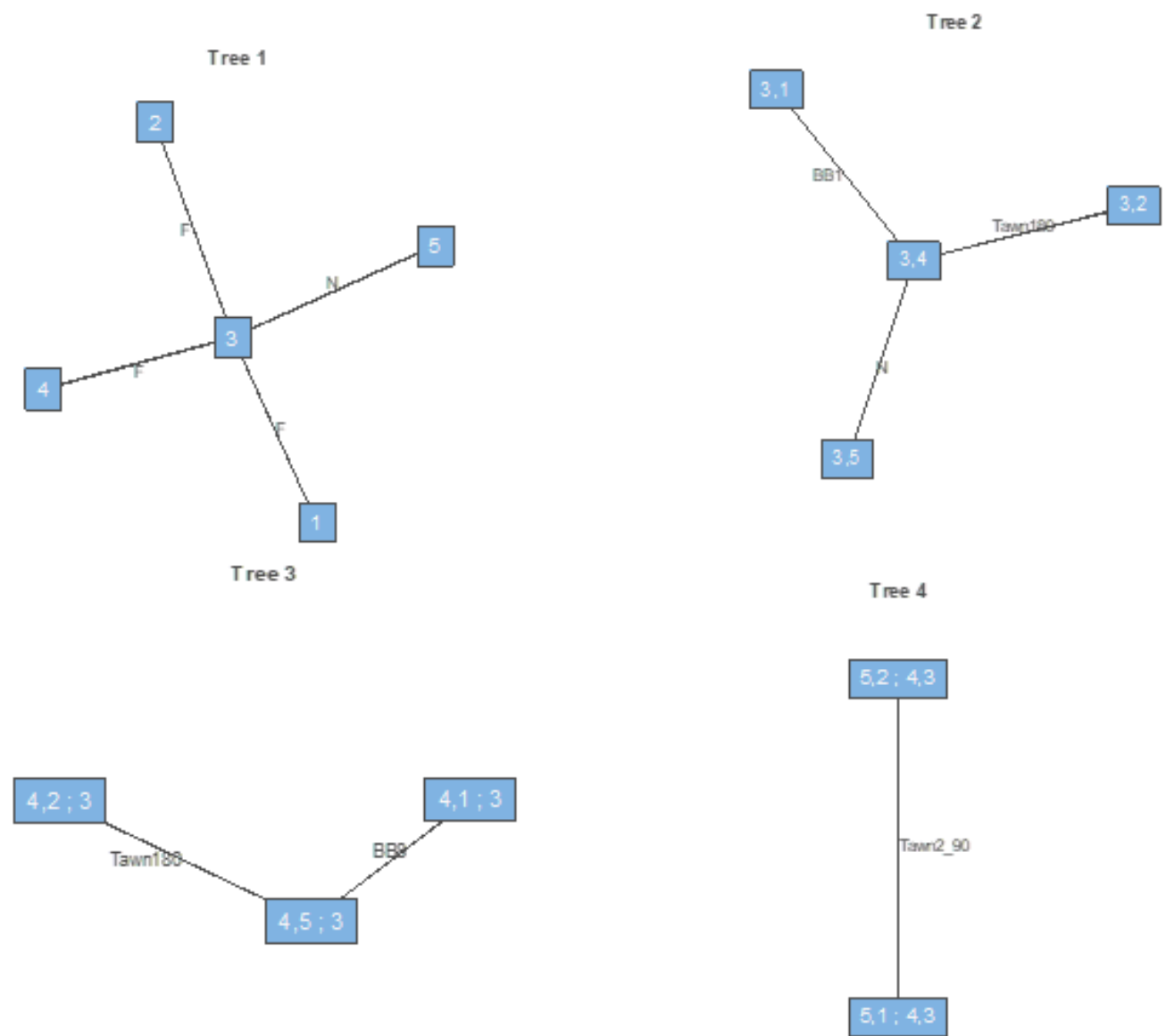

Figure 6. Tree structure of C Vine Copula Family

\subsubsection{Vine Copula Results}

Table 5. D Vine Copula Matrix Summary for Depth of North Anatolian fault line

\begin{tabular}{|c|c|c|c|c|c|c|c|c|c|c|c|c|c|c|c|c|c|}
\hline 1 & {$[, 1]$} & {$[, 2]$} & {$[, 3]$} & {$[, 4]$} & {$[, 5]$} & 2 & {$[, \mathbf{1}]$} & {$[, 2]$} & {$[, 3]$} & {$[, 4]$} & {$[, 5]$} & 3 & {$[, \mathbf{1}]$} & {$[, 2]$} & {$[, 3]$} & {$[, 4]$} & {$[, 5]$} \\
\hline$[\mathbf{1}]$, & 5 & 0 & 0 & 0 & 0 & {$[\mathbf{1}]$,} & 3 & 0 & 0 & 0 & 0 & {$[1]$,} & 3 & 0 & 0 & 0 & 0 \\
\hline$[2]$, & 1 & 3 & 0 & 0 & 0 & {$[2]$,} & 2 & 4 & 0 & 0 & 0 & {$[2]$,} & 1 & 5 & 0 & 0 & 0 \\
\hline$[3]$, & 2 & 1 & 4 & 0 & 0 & {$[3]$,} & 1 & 2 & 5 & 0 & 0 & {$[3]$,} & 2 & 1 & 4 & 0 & 0 \\
\hline$[4]$, & 4 & 2 & 1 & 2 & 0 & {$[4]$,} & 5 & 1 & 2 & 1 & 0 & {$[4]$,} & 4 & 2 & 1 & 2 & 0 \\
\hline$[5]$, & 3 & 4 & 2 & 1 & 1 & {$[5]$,} & 4 & 5 & 1 & 2 & 2 & {$[5]$,} & 5 & 4 & 2 & 1 & 1 \\
\hline \multicolumn{6}{|c|}{ AIC : -4906.765} & \multicolumn{6}{|c|}{ AIC : -4853.812} & \multicolumn{6}{|c|}{ AIC: -4831.525} \\
\hline 4 & {$[, 1]$} & {$[, 2]$} & $\begin{array}{l}, 3] \\
\end{array}$ & {$[, 4]$} & {$[, 5]$} & 5 & {$[, \mathbf{1}]$} & {$[, 2]$} & $\begin{array}{l}{[, 3]} \\
\end{array}$ & {$[, 4]$} & {$[, 5]$} & 6 & {$[, 1]$} & {$[, 2]$} & $\begin{array}{l}{[, 3]} \\
\end{array}$ & {$[, 4]$} & {$[, 5]$} \\
\hline$[1]$, & 5 & 0 & 0 & 0 & 0 & {$[\mathbf{1}]$,} & 4 & 0 & 0 & 0 & 0 & {$[1]$,} & 3 & 0 & 0 & 0 & 0 \\
\hline$[2]$, & 2 & 4 & 0 & 0 & 0 & {$[2]$,} & 1 & 5 & 0 & 0 & 0 & {$[2]$,} & 2 & 5 & 0 & 0 & 0 \\
\hline$[3]$, & 1 & 2 & 3 & 0 & 0 & {$[3]$,} & 2 & 1 & 3 & 0 & 0 & {$[3]$,} & 1 & 2 & 4 & 0 & 0 \\
\hline$[4]$, & 3 & 1 & 2 & 1 & 0 & {$[4]$,} & 3 & 2 & 1 & 2 & 0 & {$[4]$,} & 4 & 1 & 2 & 1 & 0 \\
\hline$[5]$, & 4 & 3 & 1 & 2 & 2 & {$[5]$,} & 5 & 3 & 2 & 1 & 1 & {$[5]$,} & 5 & 4 & 1 & 2 & 2 \\
\hline \multicolumn{6}{|c|}{ AIC: -4817.077} & \multicolumn{6}{|c|}{ AIC : -4807.290} & \multicolumn{6}{|c|}{ AIC : -4781.940} \\
\hline 7 & {$[, 1]$} & {$[, 2]$} & $\begin{array}{l}, 3] \\
\end{array}$ & {$[, 4]$} & {$[, 5]$} & 8 & {$[, 1]$} & {$[, 2]$} & $\begin{array}{l}{[, 3]} \\
\end{array}$ & {$[, 4]$} & {$[, 5]$} & 9 & {$[, 1]$} & {$[, 2]$} & $\begin{array}{l}{[, 3]} \\
\end{array}$ & {$[, 4]$} & {$[, 5]$} \\
\hline$[1]$, & 3 & 0 & 0 & 0 & 0 & {$[1]$,} & 5 & 0 & 0 & 0 & 0 & {$[1]$,} & 4 & 0 & 0 & 0 & 0 \\
\hline$[2]$, & 2 & 5 & 0 & 0 & 0 & {$[2]$,} & 2 & 3 & 0 & 0 & 0 & {$[2]$,} & 2 & 3 & 0 & 0 & 0 \\
\hline$[3]$, & 1 & 2 & 4 & 0 & 0 & {$[3]$,} & 1 & 2 & 4 & 0 & 0 & {$[3]$,} & 1 & 2 & 5 & 0 & 0 \\
\hline$[4]$, & 4 & 1 & 2 & 1 & 0 & {$[4]$,} & 4 & 1 & 2 & 1 & 0 & {$[4]$,} & 5 & 1 & 2 & 1 & 0 \\
\hline$[5]$, & 5 & 4 & 1 & 2 & 2 & {$[5]$,} & 3 & 4 & 1 & 2 & 2 & {$[5]$,} & 3 & 5 & 1 & 2 & 2 \\
\hline \multicolumn{6}{|c|}{ AIC : -4756.356} & \multicolumn{6}{|c|}{ AIC : -4742.229} & \multicolumn{6}{|c|}{ AIC: -4728.079} \\
\hline 10 & {$[, 1]$} & {$[, 2]$} & {$[, 3]$} & {$[, 4]$} & {$[, 5]$} & 11 & {$[, 1]$} & {$[, 2]$} & {$[, 3]$} & {$[, 4]$} & {$[, 5]$} & 12 & {$[, 1]$} & {$[, 2]$} & {$[, 3]$} & {$[, 4]$} & {$[, 5]$} \\
\hline$[1]$, & 4 & 0 & 0 & 0 & 0 & {$[1]$,} & 5 & 0 & 0 & 0 & 0 & {$[1]$,} & 3 & 0 & 0 & 0 & 0 \\
\hline$[2]$, & 1 & 3 & 0 & 0 & 0 & {$[2]$,} & 1 & 4 & 0 & 0 & 0 & {$[2]$,} & 1 & 4 & 0 & 0 & 0 \\
\hline$[3]$, & 2 & 1 & 5 & 0 & 0 & {$[3]$,} & 2 & 1 & 4 & 0 & 0 & {$[3]$,} & 2 & 1 & 5 & 0 & 0 \\
\hline$[4]$, & 5 & 2 & 1 & 2 & 0 & {$[4]$,} & 3 & 2 & 1 & 2 & 0 & {$[4]$,} & 5 & 2 & 1 & 2 & 0 \\
\hline$[5]$, & 3 & 5 & 2 & 1 & 1 & {$[5]$,} & 4 & 3 & 2 & 1 & 1 & {$[5]$,} & 4 & 5 & 2 & 1 & 1 \\
\hline \multicolumn{6}{|c|}{ AIC: -4708.560} & \multicolumn{6}{|c|}{ AIC : -4653.224} & \multicolumn{6}{|c|}{ AIC : -4612.550} \\
\hline
\end{tabular}


Table 6. D Vine Copula Family Summary for crypto money indicators

\begin{tabular}{|c|c|c|c|c|c|c|c|c|}
\hline Tree & Edge & $\begin{array}{c}\text { Family } \\
\text { No. }\end{array}$ & Copula & Par1 & Par2 & Tau & $\begin{array}{l}\text { Lower tail } \\
\text { dependency }\end{array}$ & $\begin{array}{l}\text { Upper tail } \\
\text { dependency }\end{array}$ \\
\hline \multirow[t]{4}{*}{1} & 3,5 & 1 & $\mathrm{~N}$ & 0.95 & 0.00 & 0.79 & - & - \\
\hline & 4,3 & 5 & $\mathrm{~F}$ & 27.41 & 0.00 & 0.86 & - & - \\
\hline & 2,4 & 5 & $\mathrm{~F}$ & 14.84 & 0.00 & 0.76 & - & - \\
\hline & 1,2 & 5 & $\mathrm{~F}$ & 14.63 & 0.00 & 0.76 & - & - \\
\hline \multirow[t]{3}{*}{2} & 4,$5 ; 3$ & 1 & $\mathrm{~N}$ & 0.30 & 0.00 & 0.19 & - & - \\
\hline & 2,$3 ; 4$ & 14 & SG & 1.71 & 0.00 & 0.42 & - & 0.50 \\
\hline & 1,$4 ; 2$ & 7 & BB1 & 1.39 & 1.70 & 0.65 & - & 0.75 \\
\hline \multirow[t]{2}{*}{3} & 2,$5 ; 4,3$ & 20 & SBB8 & 2.60 & 0.64 & 0.20 & - & - \\
\hline & 1,$3 ; 2,4$ & 214 & Tawn2_180 & 1.73 & 0.49 & 0.26 & - & 0.33 \\
\hline \multirow[t]{2}{*}{4} & 1,$5 ; 2,4,3$ & 10 & $\mathrm{BB} 8$ & 1.85 & 0.94 & 0.26 & - & - \\
\hline & & type: & he $\operatorname{logLik}$ & 467.38 & AIC & -4906.765 & BIC: -4849.61 & \\
\hline
\end{tabular}
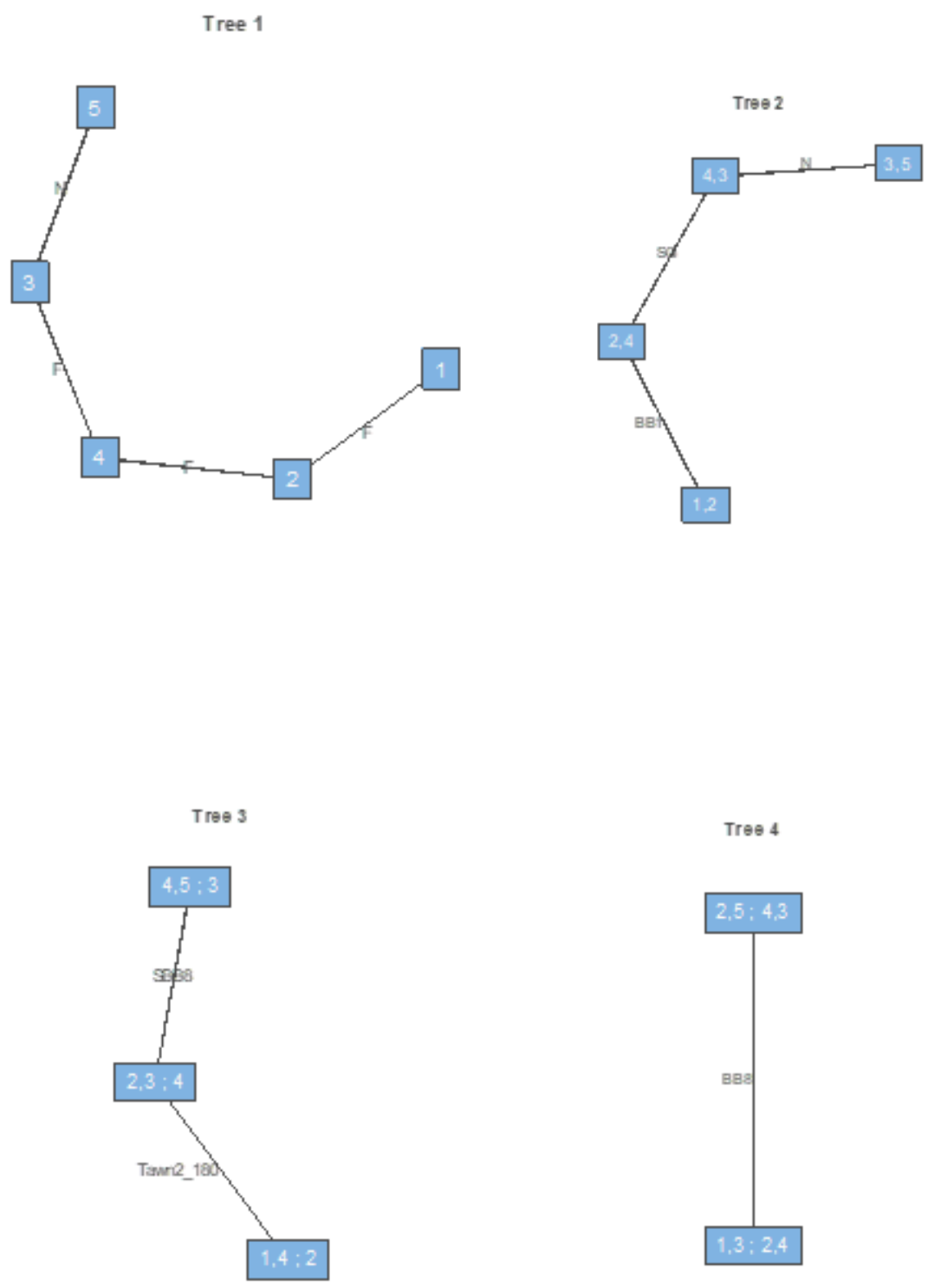

Figure 7. Tree structure of D Vine Copula Family 


\section{Conclusion}

The bivariate copulas be formed two principal classes: elliptical and Archimedean. The elliptical copulas are the Gaussian and Student-t and Archimedean copulas are the Frank, Clayton, Joe and Gumbel. The importance of bivariate copulas of from their ability to model the symmetries and asymmetries of dependence from the joint distributions. Their important restriction from their disability to efficiently model multivariate distributions in high sizes because of their normalized practice to joint distributions that separate in characteristics. The set of the pair vine copulas contains the regular, canonical and drawable, with the canonical and drawable being specific status of the regular. The major strength of the pair vine copulas lies in their resilient modelling of dependence. In this study, we search the dependence among crypto money indicators. In conclusion, we obtain that the most suitable copula for dependence structure between crypto money indicators is dynamic D-vine copula.

\section{Author's Contributions}

All authors contributed equally.

\section{Conflict of Interest Statement}

There is no conflict of interest between the authors.

\section{Research and Publication Ethics Statement}

The authors declares that this study complies with Research and Publication Ethics.

\section{References}

[1] Nakamoto S. 2008. Bitcoin: A peer-to-peer electronic cash system. https://bitcoin.org/en/bitcoin-paper (Erişim tarihi: 17.06.2020).

[2] Eyal I., Sirer E.G. 2014. Majority is not enough: Bitcoin mining is vulnerable. In International conference on financial cryptography and data security. Springer, Berlin, Heidelberg, 436-454.

[3] Grinberg R. 2012. Bitcoin: An innovative alternative digital currency. Hastings Sci. \& Tech. LJ, 4: 159.

[4] Yermack D. 2015. Is Bitcoin a real currency? An economic appraisal. In Handbook of digital currency, 31-43.

[5] Ron D., Shamir A. 2013. Quantitative analysis of the full bitcoin transaction graph. In International Conference on Financial Cryptography and Data Security, Springer, Berlin, Heidelberg 6-24.

[6] O'Dwyer K.J., Malone D. 2014. Bitcoin mining and its energy footprint. 25th IET Irish Signals \& Systems Conference 2014 and 2014 China-Ireland International Conference on Information and Communities Technologies (ISSC 2014/CIICT 2014).

[7] Garay J., Kiayias A., Leonardos N. 2015. The bitcoin backbone protocol: Analysis and applications. In Annual International Conference on the Theory and Applications of Cryptographic Techniques, Springer, Berlin, Heidelberg, 281-310.

[8] Karame G.O., Androulaki E., Capkun S. 2012. Double-spending fast payments in bitcoin. In Proceedings of the 2012 ACM conference on Computer and communications security, 906917), ACM.

[9] Reid F., Harrigan M. 2013. An analysis of anonymity in the bitcoin system. In Security and privacy in social networks, Springer, New York, NY, 197-223.

[10] Kroll J.A., Davey I.C., Felten E.W. 2013. The economics of Bitcoin mining, or Bitcoin in the presence of adversaries. In Proceedings of WEIS, 2013: 11.

[11] Bonneau J., Miller A., Clark J., Narayanan A., Kroll J.A., Felten E.W. 2015. Sok: Research perspectives and challenges for bitcoin and cryptocurrencies. In Security and Privacy (SP), 2015 IEEE Symposium on, IEEE, 104-121. 
[12] Böhme R., Christin N., Edelman B., Moore T. 2015. Bitcoin: Economics, technology, and governance. Journal of Economic Perspectives, 29 (2): 213-238.

[13] Sklar M. 1959. Fonctions de repartition an dimensions et leurs marges. Publ. Inst. Statist. Univ. Paris, 8: 229-231.

[14] Nelson R.B. 1999. An Introduction to Copulas. Vol. 39, Lectures Notes in Statistics.

[15] Embrechts P., McNeil A., Straumann D. 2002. Correlation and dependence in risk management: properties and pitfalls. Risk management: value at risk and beyond, 176223.

[16] Cherubini U., Luciano E., Vecchiato W. 2004. Copula methods in finance. John Wiley \& Sons, $1-310$.

[17] Mitchell H., McKenzie M.D. 2003. GARCH model selection criteria. Quantitative Finance, 3 (4): 262-284.

[18] Patton A.J. 2006. Modelling asymmetric exchange rate dependence. International economic review, 47 (2): 527-556.

[19] Bollerslev T. 1986. Generalized autoregressive conditional heteroskedasticity. Journal of econometrics, 31 (3): 307-327.

[20] Bollerslev T. 2009. Glossary to ARCH (GARCH. In Volatility and Time Series Econometrics: Essays in Honour of Robert F. Engle.

[21] Brooks C., Burke S.P. 2003. Information criteria for GARCH model selection. The European journal of finance, 9 (6): 557-580.

[22] Du J., Lai K.K. 2017. Modeling Dependence between European Electricity Markets with Constant and Time-varying Copulas. Procedia computer science, 122: 94-101.

[23] Albulescu C.T., Aubin C., Goyeau D., Tiwari A.K. 2018. Extreme co-movements and dependencies among major international exchange rates: A copula approach. The Quarterly Review of Economics and Finance, 69: 56-69. 